\title{
En los orígenes de la Espiritualidad de la liberación*
}

\author{
Orlando Solano Pinzón ${ }^{* *}$ \\ Mauricio Rincón Andrade***
}

Recibido: 24 de febrero de 2015 - Revisado: 18 de marzo de 2015 -

Aprobado: 10 de abril de 2015

\section{Resumen}

Este artículo realiza un acercamiento al origen de la Espiritualidad de la liberación, centrando la atención en el contexto histórico que involucra tanto acontecimientos, entre ellos los movimientos sociales de la década del sesenta del siglo anterior en el marco de los cuales se gesta y empieza a configurar sus rasgos, como personajes significativos, cuya particularidad común no es la centralidad del discurso social o teológico, sino, más bien, una vivencia de su fe que asume la realidad y se expresa en una espiritualidad y una teología coherentes con esa experiencia fundamental, la cual fue dando cuerpo a una manera particular de vivir la fidelidad a la acción del Espíritu de cara a los desafíos propios de la realidad latinoamericana. La aproximación a la fuente de la Espiritualidad de la liberación tiene el ánimo de recuperar la sensibilidad al dinamismo del Espíritu en el hoy de nuestra realidad histórica.

Palabras clave: Teología de la liberación, Espiritualidad de la liberación, experiencia de Dios, comunidades eclesiales de base.

* $\quad$ Artículo de reflexión a partir del proyecto de investigación "Espiritualidad cristiana en América Latina: evolución de sus expresiones desde Medellín hasta Puebla" (ID 004361), adelantado dentro de la línea de investigación en Espiritualidad. DOI: http://dx.doi.org/10.15332/s0120-8454.2015.0087.01

** Licenciado en Filosofía de la Universidad Santo Tomás (Bogotá, Colombia), magister y doctor en Teología de la Pontificia Universidad Javeriana (Bogotá, Colombia). Docente de tiempo completo de la Facultad de Teología de la Pontificia Universidad Javeriana, donde hace parte del grupo de investigación Academia. Dirección postal: Cra. 7 \# 40-62, Bogotá (Colombia), correo electrónico: o.solano@javeriana.edu.co

*** Estudios Eclesiásticos, Instituto Teológico San Esteban - Universidad Pontificia de Salamanca (España); licenciado en Teología, Universidad San Buenaventura; especialista y magíster en Bioética, Universidad El Bosque. Docente de tiempo completo del Centro de Formación Teológica de la Facultad de Teología de la Pontificia Universidad Javeriana. Miembro del grupo de investigación Didaskalia. Dirección postal: Cra. 7 \# 40-62, Bogotá (Colombia), correo electrónico: mauricio-rincon@javeriana.edu.co 


\title{
In the origin of Spirituality of liberation*
}

\author{
Orlando Solano Pinzón ${ }^{* *}$ \\ Mauricio Rincón Andrade***
}

This article makes an approach to the origin of the Spirituality of liberation, focusing on the historical context that involves both events, including the social movements of the sixties of the last century in the context where it is conceived and its features start taking shape, as well as significant characters, whose common characteristic is not the centrality of the social or theological discourse, but rather, an experience of faith that assumes the reality and expresses in a spirituality and a theology consistent with this fundamental experience, which gave shape to a particular way of living fidelity to the Spirit's action in the face of the unique challenges of the Latin American reality. The approach to the source of the Spirituality of liberation has the intention to regain sensitivity to the dynamism of the Spirit in our historical reality today.

Keywords: Liberation theology, Spirituality of liberation, experience of God, basic ecclesial communities

Reflection article from the research project "Christian Spirituality in Latin America: their expressions from Medellin to Puebla" (ID 004 361), advance in the research on spirituality.

** Degree in Philosophy from Universidad Santo Tómas (Bogota, Colombia), master's and doctorate in theology from the Pontificia Universidad Javeriana (Bogota, Colombia). Full-time faculty of the School of Theology of the Pontifical Javeriana University, where he is part of the research group Academy. Address: Cra 7 \# 40-62, Bogota (Colombia), e-mail: o.solano@javeriana.edu.co

*** Ecclesiastical Studies, St. Stephen's Theological Institute - Pontifical University of Salamanca (Spain); Bachelor of Theology, University of San Buenaventura; Specialist and Master in Bioethics, University Forest. Full-time faculty of the Center for Theological Education of the Faculty of Theology at the Pontificia Universidad Javeriana. Member of the research group Didaskalia. Address: Cra 7 \# 40-62, Bogota (Colombia), e-mail: mauricio-rincon@javeriana.edu.co 


\title{
Aux origines de la Spiritualité de la libération*
}

\author{
Orlando Solano Pinzón ${ }^{* *}$ \\ Mauricio Rincón Andrade***
}

Cet article évoque une approche à l'origirne de la Spiritualité de la libération, en centrant l'attention dans le contexte historique qui implique aussi bien des faits, tels que les mouvements sociaux des années soixante du siècle passé dans le cadre desquels se prépare et commence à se configurer ses traits, comme aussi des personnages significatifs, dont leur singularité commune n'est pas la centralité du discours social ou théologique, mais plutôt une expérience de leur foi qui assume la réalité et s'exprime dans une spiritualité et une théologie cohérentes avec cette expérience fondamentale, laquelle a peu à peu donnée place a une manière particulière de vivre la fidélité à l'action de l'Esprit face aux défis propre à la réalité latino-américaine. L'approche à la source de la Spiritualité de la libération a pour but de récupérer la sensibilité au dynamisme de 1'Esprit dans le présent de notre réalité historique.

Mots clés: Théologie de la libération, Spiritualité de la libération, expérience de Dieu, communautés ecclésiastiques de base.

* L'article de réflexion du projet de recherche «La spiritualité chrétienne en Amérique latine: leurs expressions de Medellin à Puebla" (ID 004 361), avancer dans la recherche sur la spiritualité.

** Licence de Philosophie de l'Université St. Thomas (Bogota, Colombie), de maîtrise et de doctorat en théologie de la Pontificia Universidad Javeriana (Bogota, Colombie). Professeurs à temps plein de la Faculté de Théologie de l'Université pontificale Javeriana, où il fait partie du groupe de recherche Académie. Adresse: Cra 7 \# 40-62, Bogota (Colombie), e-mail: o.solano@javeriana.edu.co

*** Études ecclésiastiques, Institut théologique de Saint-Etienne - Université pontificale de Salamanque (Espagne); Bachelor of Theology, Université de San Buenaventura; Spécialiste et maîtrise en bioéthique, université de forêt. Professeurs à temps plein du Centre pour l'éducation théologique de la Faculté de Théologie de la Pontificia Universidad Javeriana. Membre du groupe de recherche Didaskalia. Adresse: Cra 7 \# 40-62, Bogota (Colombie), e-mail: mauricio-rincon@ javeriana.edu.co 


\section{Introducción}

El presente artículo pretende un acercamiento al origen de la Espiritualidad de la liberación, conscientes de que el ejercicio teológico realizado en América Latina, buscó integrar nuevamente espiritualidad y teología como dos caras de la misma moneda. Por este motivo, al hacer énfasis en la Espiritualidad de la liberación, no queremos desligarla de la reflexión sistemática sino resaltar la dimensión espiritual que ha estado rezagada en la producción teológica. Dada la aclaración, el objetivo a desarrollar apunta a identificar los factores que hicieron posible el surgimiento de una nueva manera de vivir el encuentro con Dios, y ser fiel a la acción de su Espíritu en la realidad histórica de las comunidades eclesiales de América Latina de finales de la década del 60 e inicios de la década del 70.

En este sentido, en primer lugar, se hará referencia a las características sociales, políticas, económicas y eclesiales del contexto de gestación de la Espiritualidad de la liberación y a los personajes más representativos que contribuyeron a sistematizar dicha experiencia espiritual; posteriormente, se evocará la experiencia fundamental, dando cuenta, a través de unos rasgos, de la forma como dio lugar a una nueva manera vivir la fidelidad a la acción del Espíritu.

\section{El contexto}

Puesto que "toda gran espiritualidad está ligada a los grandes movimientos históricos de su época" (Gutiérrez, 1983, p. 45) y toda teología parte de una profunda experiencia espiritual, es preciso caracterizar el contexto latinoamericano entre 1968 y 1979 para dar cuenta del proceso de gestación de la Espiritualidad de la liberación en este continente. Según Gutiérrez (1975):

La espiritualidad que subyace a la Teología de la liberación tiene como entorno de gestación los movimientos de liberación presentes en las diferentes latitudes del subcontinente, que en medio de las condiciones de inhumana pobreza, explotación y sometimiento, fueron creando conciencia de esta situación y aspiraban a la liberación integral de todo aquello que limitaba e impedía el ejercicio de la libertad y la realización de los seres humanos (p. 66).

América Latina pasa por una serie de circunstancias sociales, políticas, económicas y eclesiales que no solo marcarán la forma de hacer la reflexión teológica, sino la misma vida de millones de latinoamericanos. Estos aspectos se relacionan mutuamente y configuran un espacio propicio, para que junto a la Teología de la liberación surja una verdadera Espiritualidad de la liberación. En las conclusiones de la Segunda Conferencia del Episcopado Latinoamericano realizada en Medellín en 1968, se hizo "un sucinto diagnóstico de la situación latinoamericana" (Medellín, 1987, pp. 33-36). Dicho diagnóstico se dividió en tres grandes tensiones que nos pueden servir de marco para entender, a 
grandes rasgos, lo que estaba sucediendo en América Latina: 1. Tensiones entre clases y colonialismo interno; 2 . Tensiones internacionales y neocolonialismo externo; 3. Tensiones entre los países de América Latina. En relación con la primera tensión, hay que mencionar aspectos tales como: diversas formas de marginación, desigualdades excesivas entre clases sociales, formas de opresión de grupos y sectores dominantes, poder ejercido injustamente por ciertos sectores y la creciente toma de conciencia de los grupos oprimidos. En este primer apartado es fundamental subrayar la terrible situación de pobreza que viven millones de personas que, junto a otros aspectos, complican la situación, llevando a muchos latinoamericanos a vivir, o sobrevivir en muchos casos, en una escandalosa miseria.

En lo que tiene que ver con la segunda tensión, Medellín nos recuerda que en el subcontinente nuestros países viven una dependencia de un centro de poder económico, nos encontramos con una distorsión creciente del comercio internacional en donde las materias primas, muchas producidas en Latinoamérica, valen cada vez menos y los productos manufacturados, cada vez más; pero, además, asistimos a una fuga de capitales económicos y humanos, un endeudamiento progresivo y unos monopolios económicos internacionales que influyen cada vez más en las políticas de nuestros países y que de una manera directa coadyuvan a la situación de pobreza que se vive.

En relación con la última tensión, nos encontramos con distintas formas de imperialismo que se ejerce en América Latina en forma directa e indirecta, nacionalismos exacerbados y hasta el proceso armamentístico de muchos países de la región. Toda esta situación que vive América Latina hace que en la década de los setenta muchos militares se tomen el poder con la excusa de reestructurar el Estado, superar los problemas económicos y reorganizar la sociedad en su conjunto. Entre los países que en esta época van a sufrir dictaduras militares están Chile, Bolivia, Argentina, Brasil y Uruguay. Esta coyuntura hace que la situación en lugar de mejorar se empeore, sobre todo en lo que tiene que ver con la violación sistemática de los Derechos Humanos. Un ejemplo de ello es el Plan Cóndor, que básicamente consistió en un programa de ayuda y apoyo mutuo de los regímenes dictatoriales que se inició en la década de los setenta y en donde se persiguió, encarceló injustamente, torturó, desapareció y hasta se asesinó a miles de personas opositoras o que no comulgaban con la política realizadas por los dictadores de la región.

En este contexto que vive América Latina es fundamental acercarnos también a los acontecimientos eclesiales que permitirán no solo el surgimiento de la Teología de la liberación, sino de la misma Espiritualidad de la liberación. Podemos mencionar: Vaticano II, Medellín y Puebla. Vaticano II (1962-1965) será un verdadero acicate para que la Iglesia se abra al mundo y para que la teología reflexione a partir de la realidad de los pueblos de una manera crítica a la luz de la fe (GS 1-11). Las circunstancias históricas por las cuales atraviesan nuestros pueblos latinoamericanos, especialmente el tema de la pobreza, harán que esta invitación del Vaticano II se convierta en una experiencia fundante que trazará 
unas líneas propias que darán cuerpo a una experiencia espiritual que estará a la base de la reflexión teológica en el subcontinente. En relación con esto podemos preguntarnos: “ ¿cuál fue la experiencia e intuición originales de las que brota la Teología de la liberación? No fue otra que la experiencia cotidiana de la injusta pobreza en que son obligados a vivir millones de hermanos latinoamericanos" (Oliveros, 1990, p. 18). Oliveros, en su artículo sobre la Historia de la Teología de la liberación, nos dice que no podemos olvidar que en aquel entonces los episcopados latinoamericanos, por su escasa participación en el Concilio, fueron denominados la "Iglesia del silencio". Pero gracias a las intuiciones del Concilio y al compromiso y reflexión de muchos cristianos en América Latina a mediados de 1966, nos encontramos con hondos deseos en promover cambios sociales, esto finalmente va a desembocar en uno de los hitos más importantes de la historia de la Iglesia latinoamericana en el siglo XX: la Segunda Conferencia del Episcopado Latinoamericano en Medellín (1968).

Los temas fundamentales tratados en Medellín los podemos sintetizar en tres: 1. Los pobres y la injusticia; 2 . Amor al hermano y la paz en una situación de violencia institucionalizada; 3 . Unidad de la historia y dimensión política de la fe. En la introducción del documento conclusivo podemos leer:

No basta con cierto reflexionar, lograr mayor clarividencia y hablar; es menester obrar. No ha dejado de ser esta la hora de la palabra, pero se ha tornado, con dramática urgencia, la hora de la acción. Es el momento de inventar con imaginación creadora la acción que corresponde realizar, que habrá de ser llevada a término con la acción del Espíritu y el equilibrio de Dios (Medellín, 1987, p. 18).

Las orientaciones y profundizaciones de Medellín cristalizarán, entre otras cosas, en el libro de Gustavo Gutiérrez: Teología de la liberación. Perspectivas. Entre 1972 y 1979, encontramos una serie de sucesos que hicieron que muchas intuiciones de Medellín y del mismo libro de Gutiérrez siguieran reflexionando y aparezcan nuevas cuestiones y aportes: el encuentro de El Escorial (8-15 de julio de 1972); el encuentro en México (11-15 de agosto de 1975); el encuentro de Detroit (18-24 de agosto de 1975); el encuentro de Dar es Salaam (5-12 de agosto de 1976) y finalmente la convocatoria y preparación de la Tercera Conferencia del Episcopado Latinoamericano que se realizaría en Puebla, México. Esta conferencia se realizó en 1979 y según Oliveros (1990):

Puebla respondió a las graves cuestiones que se le plantearon. Clara y repetidamente alabó a Medellín y su profetismo. Subrayó que la misión, hoy, de la Iglesia está en la práctica de la liberación en el espíritu de Jesús. Recogió, aprovechó y reimpulsó el servicio de la Teología de la liberación (p. 37).

Esta nueva manera de comprender la acción del Espíritu, además de configurar un modo de existencia encarnado en las realidades históricas, fomentó el crecimiento de las comunidades eclesiales de base (CEB). Estas CEB están en la línea del Vaticano II, Medellín y Puebla. Ellas tratan de reactualizar las características 
y el dinamismo de las primeras comunidades cristianas, adaptándose a los tiempos actuales. Como indica Iriarte (1993):

Los elementos constitutivos de las CEB son: mantener e intensificar en el grupo relaciones de amistad, de apoyo mutuo, de solidaridad, de fraternidad y de perdón; tener fe en Jesús Salvador y querer profundizarla, junto con la amistad se comparte también la fe, se renueva y fortalece; comprometerse con el mundo en que se vive, buscando que se llegue a una acción más solidaria, más consciente y más eficaz (p. 15).

Todos estos contextos descritos no solo permitirán que surja y se desarrolle un tipo propio de hacer teología desde América Latina, sino también gestó la misma Espiritualidad de la liberación. Jon Sobrino (1990) nos dirá al respecto:

La Teología de la liberación habla de la necesidad de la espiritualidad. La liberación, la práctica de la justicia, la construcción del reino es algo irrenunciable; pero esa decisión fundamental por la vida de los pobres tiene que estar llena de espíritu. Ambas cosas se ven como necesarias y como mutuamente potenciadoras (p. 508).

Si bien a la Teología de la liberación se le criticó injustamente la ausencia de espiritualidad, ello obedece a que su espiritualidad se gestó al margen de las prácticas tradicionales y fue emergiendo en la experiencia vital de quienes estaban implicados en el proceso de liberación. En muchos aspectos de su vida actual, dirá Gutiérrez, "no tienen detrás de ellos una tradición teológica y espiritual. Ellos mismos la están forjando" (1975, p. 267).

Solo en un segundo momento de reflexión, autores como Leonardo Boff, Segundo Galilea, Jon Sobrino, Camilo Maccise, Ignacio Ellacuría, entre otros, fueron haciendo un ejercicio de reinterpretación y resignificación de las categorías tradicionales de la espiritualidad desde el lugar teológico que representan los pobres y el dinamismo del Espíritu que se despliega en el anhelo de liberación. Estos autores son considerados, en el contexto europeo, precursores e iniciadores de la reflexión teológica latinoamericana de la liberación. Sus pensamientos son referidos por teólogos como Xavier Pikaza, José María Castillo o Juan Martín Velasco, quienes en sus obras aluden a ellos como las figuras que representan el nacimiento y desarrollo de la espiritualidad y de la teología latinoamericana de la liberación.

\section{Personajes}

En Gustavo Gutiérrez (1928), como en muchos otros, su itinerario vital e intelectual resulta inseparable. Más aún si se trata de la reflexión sobre la fe que se vivencia. Su ser de teólogo refleja la persona que es y la realidad social y humana que le circunda. Por ello ha afirmado: "se cree en Dios a partir de 
una situación histórica determinada; el creyente forma parte [...] de un tejido cultural y social", luego, "se intenta pensar esa fe" (Gutiérrez, 1989, p. 18). Su experiencia infantil y juvenil le pone desde muy pronto en contacto con el dolor que experimenta a raíz de sus quebrantos de salud, provocando en él una sintonía particular con el mundo y el entorno del sufrimiento, el padecimiento de tantos seres humanos en situación de pobreza. El hallazgo del Dios del Evangelio, en profunda cercanía con el dolor de sus hijos, junto con la excelente formación teológica recibida en Europa, van configurando en él su estilo particular de pensar y de escribir. En últimas, el sentido de toda su vida y su obra se evidencia en la estrecha relación entre su itinerario vital, su experiencia espiritual y su producción intelectual.

Segundo Galilea fue un sacerdote chileno (1928-2010), ordenado en 1956, en su momento, director del Instituto Pastoral Latinoamericano, hoy ITEPAL. Una vida tras las huellas del Espíritu, en profunda sintonía con la realidad y las demandas del cristianismo latinoamericano. Para muchos, su vida estuvo dedicada a favorecer el encuentro con Dios en las personas desde una profunda conciencia de la realidad social y religiosa. La fuerza de sus escritos no tiene otra fuente que su propia vida de oración, su sencillez y su generosidad: una vida desde el Evangelio. Para Galilea la espiritualidad es la savia de la pastoral, de la teología y de la comunidad, sin ella no es posible construir una vida cristiana. Según Pikaza (2010), es un teólogo que vio la necesidad de vincular el compromiso liberador con una experiencia contemplativa, abierta al encuentro con Dios, por medio de los otros, rescatando la hondura divina de la vida humana, experimentada como lugar de encuentro personal en gratuidad.

Leonardo Boff nació en Concordia Brasil (1938), se formó en un ambiente de espiritualidad franciscana y se doctoró en 1972 en Munich bajo la dirección de Rahner. Fue profesor de Teología Sistemática y de Espiritualidad en Petrópolis y en varias universidades de Brasil y de Europa. Aunque actualmente su reflexión y sus escritos han dado un giro hacia la Teología de la ecología, en su obra y su pensamiento permanece vigente el tema de la Espiritualidad, sobre el cual realizó una primera reflexión en 1974 (Boff, 1975) dirigida a los religiosos, como resultado de la solicitud explícita de la Conferencia de Religiosos del Brasil.

Ignacio Ellacuría (1930-1989) nació el 9 de noviembre en Portugalete (Vizcaya, España). En 1949 estudia Humanidades y Filosofía en la Universidad Católica de Quito (Ecuador), obteniendo su licencia, civil y eclesiástica en 1955. De 1958 a 1962 estudia Teología en Innsbruck, donde tiene entre sus maestros a Karl Rahner. En 1962 inicia su doctorado en Madrid (España), donde conoce al filósofo Xavier Zubiri, con quien tendrá una gran amistad y afinidad intelectual que le llevará a quedar como heredero intelectual de su obra y como director del seminario Xavier Zubiri con sede en Madrid. En 1967 inicia su labor en la UCA del Salvador, que le llevará a pasar por diferentes cargos, entre ellos: clases de filosofía, miembro de la junta de directores, jefe del departamento de Filosofía, director de la revista de Estudios Centroamericanos (ECA), rector de 
la UCA y vicerrector de Proyección Social. Además, impartió cursos, dirigió seminarios y dictó conferencias en América Latina, Europa y Estados Unidos. El 16 de noviembre de 1989 muere asesinado junto a otros 5 de sus cohermanos y una trabajadora con su hija.

Para entrar en sintonía con el pensamiento de Ellacuría, es importante tener presente que su teología nace de una experiencia personal enmarcada en el tiempo y en el espacio. Por este motivo, cuando se realiza el rastreo por las motivaciones que le llevaron a interesarse por lo político es necesario referir tres hechos concretos, a saber: 1. La experiencia personal y académica con la obra de Zubiri, cuya filosofía de la realidad le dio una sensibilidad y un instrumental metodológico que le ayudaría a canalizar la reflexión; 2. La llamada a la Iglesia por parte del Concilio Vaticano II a una apertura al mundo, compartiendo "los gozos y las esperanzas, las tristezas y las angustias de los hombres de nuestro tiempo, sobre todo de los pobres y de cuantos sufren" (Vaticano II, Gaudium et spes); 3 . La escucha del clamor de los pueblos y de las clases oprimidas, pero recogido efectivamente en los movimientos socio-políticos de la liberación, que lo habían articulado en distintas formas de lucha política.

Aunque su ciudad natal es Barcelona, Jon Sobrino (1938) ha vivido en Centroamérica desde 1974, donde se consagró como profesor de la UCA del Salvador, y sobrevivió al asesinato del que Ignacio Ellacuría y sus compañeros fueron víctimas. Su opción por el Evangelio se ha mantenido firme, contribuyendo con una teología del seguimiento de Jesús, comprometida con la realidad social y fundada en una experiencia espiritual de la misericordia de Dios. Su opción y compromiso con el Evangelio y con los pobres le llevó a producir una teología que no estuvo al margen de críticas y condenas por parte de algunos sectores de la Iglesia. Su labor es incansable y su palabra respetada en muchos escenarios de Europa y América. A través de su obra es posible reconocer que la espiritualidad no es una realidad separada de la vida, el sujeto espiritual es constante referencia a sus hermanos y a Dios en medio de la historia.

Camilo Maccise (1937-2012), hijo de padre libanés, fue un mexicano cuya sencillez y sentido del humor no le impidió ser Superior General de la Orden de los Carmelitas Descalzos (1991-2002) y presidente de la Unión de Superiores Religiosos (1994-2001). Durante la década del 70, fue amigo y coautor de escritos con otros teólogos latinoamericanos como Leonardo Boff. En sus conversaciones y escritos nunca dejó de denunciar el mal que causan el poder y la violencia al interior de la Iglesia. Su comprensión de la espiritualidad pasa necesariamente por la realidad de los pobres, y gran parte de su reflexión y escritos los encaminó a la vida religiosa, como un aporte singular desde su experiencia de vida y su itinerario espiritual. Para Camilo Maccise la espiritualidad acontece entre los pobres, los solidarios, los anawim. Comprendió la mística en el ámbito de la lucha por la liberación de los oprimidos. 


\section{La experiencia fundamental}

Después de describir las particularidades del contexto en el cual se gestó la Espiritualidad de la liberación y hacer referencia a los personajes más representativos que hicieron un aporte sistemático para dar cuenta de la espiritualidad emergente, en este apartado la atención se centrará en los dos elementos que constituyen la experiencia fundamental y, por ende, el eje central de la misma, ellos son: la aspiración a la liberación y la experiencia de encuentro con Dios en el pobre.

\section{Aspiración a la liberación}

Como se afirmó en el apartado anterior, la Espiritualidad de la liberación se gesta en los movimientos sociales de la década del sesenta en América Latina. En medio de las habituales condiciones de inhumana pobreza y de explotación en el subcontinente, muchos hombres y mujeres, conscientes de su situación, se organizaron para luchar juntos en favor de su liberación.

En este contexto, la liberación no solo expresaba las aspiraciones de las clases sociales y pueblos oprimidos, sino que también hacía evidente el aspecto conflictual del proceso económico, social y político que somete a dichos pueblos a las pretensiones de las clases opresoras. En esta realidad conflictual, la liberación aparece como una exigencia del despliegue de todas las dimensiones humanas y, por este motivo, como liberación integral.

Debido a su origen en los movimientos sociales, el concepto liberación llegó a los teólogos latinoamericanos como un término político, como un clamor de protesta ante estructuras económicas y sociales vividas como injustas que les llevó a asumir una actitud de preocupación e implicación progresiva, además de orientar, desde esa cruda realidad, su reflexión acerca de Dios, de la Iglesia y del hombre. Lo anterior, desde el espíritu de apertura al mundo del Vaticano II, que para ellos lo constituye América Latina. Al respecto, afirma Ellacuría (1993):

En el origen de la Teología de la liberación hay un dejarse impactar y afectar por la realidad verdadera, no solo por su concepto o por su significado. Por esa razón, la teología va a estar guiada por el "principio realidad", con lo cual va a ser una teología sustancialmente "histórica", y no solo una teología "cultural" porque el "sentido" fuese su problema, y va a ser una teología "espiritual", pues la realidad que impacta es tal, que llega a todas las dimensiones del espíritu del ser humano. Pues bien, la realidad que se descubre es la "irrupción del pobre" (p. 205).

En esta disposición para afrontar la realidad tal cual es, cobra gran importancia la mirada atenta a la praxis, a la acción, al acontecer eclesial, a la experiencia espiritual de las comunidades eclesiales, porque la teología es siempre reflexión 
acerca de la experiencia histórica que los hombres tienen de Dios, y esa experiencia se da sobre todo en la praxis.

Teólogos tales como Ellacuría (1993) tienen claro que "el diálogo con las nuevas corrientes sociales que debe hacer la teología no implica cristianizar los movimientos políticos de liberación; la liberación es en principio una tarea histórica y, dentro de la historia, una tarea socioeconómica" (p. 325).

...La liberación es, por lo pronto, un proceso. Un proceso que en lo personal es fundamentalmente un proceso de conversión y que en lo histórico es un proceso de transformación, cuando no de revolución... Ni en lo personal ni en lo histórico puede hablarse de libertad si no se dan condiciones materiales y objetivas para ella... De ahí que una lucha auténtica por la libertad exige la transformación de aquellas condiciones reales que impiden o dificultan al máximo la libertad socio-política y económica de la mayor parte de un pueblo. La liberación de las estructuras injustas y la creación de nuevas estructuras, fomentadoras de la dignidad y de la libertad, se constituyen por tanto en camino esencial de la libertad, de la libertad para los individuos dentro de su contexto nacional y libertad para los pueblos dentro de su contexto internacional (Mora, 1999).

Si bien es cierto, en un primer momento se asume la liberación respetando su autonomía temporal, posteriormente al mirar hacia la fe, se reconoce que la teología cristiana es esencialmente soteriológica, particularmente el anuncio cristiano es un mensaje de salvación y es en torno de esta palabra donde la teología debe girar. En efecto, aquí ya no se habla de liberación política y estructuras económicas, sino de salvación y de lenguaje teológico. Dios salva al hombre de todo lo que le impide ser hombre. "La salvación cristiana no consiste en ausencia de pecado sino en la plenitud de vida" (Ellacuría, 1971, p. 78).

El hecho de mirar hacia la fe hace que los teólogos latinoamericanos centren su atención en la Sagrada Escritura y encuentren, en un primer momento en la experiencia veterotestamentaria y posteriormente en la conducta paradigmática de Jesús de Nazaret, que el Dios de Israel y el Abbá, al cual se dirige Jesús, es un Dios liberador. Al respecto, irán emergiendo multitud de referencias bíblicas donde podrá evidenciarse la liberación de carácter histórico.

Sobre este punto particular, Ellacuría recuerda que no solo se puede afirmar que en el Antiguo Testamento la salvación atraviesa lo político, sino que ella es inicialmente liberación política: "Israel entendió su salvación desde su propia liberación histórica. En su propia historia de pueblo, antes que de individuos, y de pueblo con problemas concretos de índole predominantemente política, es donde la Palabra de Dios fue tomando carne [...]" (Ellacuría, 1971, p. 65).

En la experiencia de Israel, liberación política e interpretación teologal en clave soteriológica de esa liberación, son inseparables, aun cuando también sean inconfundibles, puesto que lo ocurrido no es idéntico a lo interpretado. Lo 
acontecido es político y lo significado es salvífico. Esta claridad que evidencia que todo sucedió en un solo hilo histórico de acontecimientos lleva a Ellacuría a desarrollar una reflexión sobre la unidad de la historia.

Frente a la crítica que recibió la Teología de la liberación por su marcado acento veterotestamentario, Ellacuría arguye que el momento veterotestamentario de la Teología de la liberación no le cierra a ella lo esencial de la experiencia cristiana, en efecto, ni el Antiguo Testamento es solo "carne histórica", ni el Nuevo Testamento es solo "espíritu": "en ambos casos hay espíritu y carne, Dios e historia, tan inseparablemente unidos, que la desaparición de uno traería consigo la desfiguración, cuando no, la destrucción del otro" (Ellacuría, 1987).

En aras de continuar desarrollando la reflexión y queriendo responder a la crítica antes mencionada, los teólogos de la liberación afianzan su referencia al Nuevo Testamento, elaborando un discurso acerca de Jesucristo Liberador y acerca de la relación entre la cruz de Cristo y la cruz de las mayorías oprimidas. Los teólogos van al núcleo de la fe, la resurrección del Señor, pero recordando que el resucitado no es otro que el crucificado, y que el crucificado no es otro que el Jesús histórico.

La figura del Jesús histórico no solo revela una imagen escandalosa de Dios y una revolución en la concepción de lo religioso, sino que da la clave para encontrar en los más oprimidos una nueva presencia del Jesús histórico y un principio de revelación cristiana (Sols, 1999, p. 101).

Tal como afirma Ellacuría citado por Sols (1999):

Como quienes no quieran ver el compromiso histórico y, a veces, político que exige la fe en Jesús resucitado, que es en identidad de persona y en continuidad de vida el Jesús crucificado, muerto por nuestros pecados, pero asesinado por los poderosos de su tiempo (p. 92).

En aras de resumir el argumento de lo expuesto en el presente apartado, es posible afirmar que la referencia a la liberación es, en un primer momento, una interpelación de la realidad histórica a hombres de fe, quienes interpretan dicha realidad desde su experiencia profunda de fe, reconociendo el mensaje liberador propio de la Escritura y la acción salvadora de Dios en la historia.

Ahora bien, en la medida en que los diversos grupos del pueblo de Dios, que constituyen una minoría, van haciendo consciente su situación, se van involucrando gradualmente y en forma variada en el proceso de liberación. Al interior de dicho proceso, que incluye luchas, desolación, muerte anticipada, pero también alicientes y satisfacciones, la espiritualidad tradicional se quedó corta para acompañar y dinamizar el proceso de liberación, por ello, Gutiérrez (1989) señalará "la necesidad urgente de elaborar una Espiritualidad de la liberación 
que sea capaz de echar sus raíces en la realidad caracterizada por la situación de opresión-liberación" (pp. 178-268).

Además, la "liberación" no se entiende como un hecho puntual, sino como un dinamismo, por tanto, se asume como un proceso que se convierte en lugar teológico relevante y revelador dentro de la reflexión y vida cristianas. La participación en dicho proceso, según Gutiérrez (1989), "permite adquirir una vivencia más concreta de esa situación de dominación, percibir su densidad, y lleva a desear conocer mejor sus mecanismos" (p. 113).

En correspondencia con lo anterior, Gutiérrez (1989) indica que "hablar de liberación permite otro tipo de aproximación que nos conduce a las fuentes bíblicas que inspiran la presencia y el actuar del hombre en la historia" (pp. 6869). Particularmente, en la narrativa neotestamentaria, Jesucristo se nos presenta como el Salvador que libera al hombre del pecado, raíz última de toda ruptura de amistad, de la injusticia y la opresión, haciéndolo auténticamente libre, para vivir en comunión con Él y en comunión con toda la humanidad.

\section{Experiencia de encuentro con Dios en el pobre}

El testimonio de la Escritura permite comprender que Dios se hace presente en la vida de los seres humanos de muchas maneras, y esa variedad de formas de presencia, según Gutiérrez (1975):

Condicionan las formas de nuestro encuentro con él. Más aún, si la humanidad, si cada hombre es el templo vivo de Dios, a Dios lo encontramos en el encuentro con los hombres, en el compromiso con el devenir histórico de la humanidad (pp. 250-251).

Al interior de las diferentes comunidades eclesiales que padecían la inhumana pobreza y que se habían hecho conscientes de su situación, la fe en el Dios encarnado en Jesucristo les permitió vivir la experiencia de encuentro con Dios en el encuentro con los pobres. Lo anterior, permite comprender la hondura de dicha experiencia de Dios y, por ende, de la Espiritualidad de la liberación que se hizo evidente, que no surgió como fruto de una moda o un slogan, sino del encuentro y la honestidad con la cruda realidad histórica.

Dicha experiencia configuró una nueva forma de existencia que daba cuenta de la acción del Espíritu, y que al sistematizarse dio lugar a una manera alternativa de hacer teología, de interpretar la acción del Espíritu en la consolidación del proceso de liberación integral. Este proceso a su vez reafirmó una nueva conciencia del ser y quehacer de la Iglesia emergente del Concilio Vaticano II que se comenzó a consolidar en América Latina en la Segunda Conferencia General del Episcopado (1968) realizada en Medellín. Según Maccise (2007):

La temática conciliar y algunas de sus líneas teológicas influyeron decisivamente en su gestación. Fue, sobre todo, la Constitución 
Gaudium et spes, con su teología de los signos de los tiempos, la que llevó a la Iglesia a un acercamiento a la realidad del continente (p. 1).

Debido a la particularidad de la experiencia de Dios y a la fidelidad al dinamismo del Espíritu que generó un estilo de vida comprometido con los anhelos de liberación, esta nueva experiencia espiritual pasó en un primer momento desapercibida, puesto que sus expresiones empezaron a desarrollarse al margen de la espiritualidad y prácticas religiosas tradicionales. Estas expresiones nuevas de la espiritualidad se afirmaron en la historia como modos de acción del Espíritu que los teólogos de la liberación que hablaron sobre espiritualidad, lograron tematizar y sistematizar.

Poco a poco la espiritualidad tematizada se hace expresión del dinamismo interno que moviliza el proceso de liberación integral que no desconoce la esfera de lo político y debe entenderse como "todo lo que está implicado en el término sociedad y no solamente la relación formal con el Estado" (Assmann, 1971, p. 13).

Muy pronto empezó a ser reconocido por miembros de la Iglesia el significado espiritual del conjunto de motivaciones que animaban a estas personas. En las ansias de liberación del pueblo marginado y en sus esfuerzos por organizarse con el fin de conseguir una vida realmente digna, muchos cristianos comenzaron a descubrir el surgimiento de una nueva espiritualidad.

Para Gutiérrez (1975, pp. 250-251), la espiritualidad como fuente de la teología no se comprende sin la base de una experiencia espiritual, un sentir de la presencia de Dios en el encuentro con el hermano que se vive como experiencia de Dios. El encuentro con los pobres y la experiencia de Dios que de allí emerge tienen por tanto un carácter profundamente comunitario-eclesial en donde el Reino se manifiesta, pues "el reino de Dios es, a una, la presencia activa de Dios en la historia y la presencia de la historia en Dios, la historización de Dios [...] es, en definitiva, el Dios-con-nosotros" (Ellacuría, 1984, p. 17).

En esta forma de presencia histórica del Reino, la fuerza y profundidad de la experiencia de Dios, se hace visible y palpable en el encuentro con los pobres de un modo que no es aislado ni individual, aunque sí supone una experiencia de soledad, que hace parte de la dimensión mística de toda espiritualidad.

Dentro de los esfuerzos de sistematización de la experiencia fundamental que está a la base de la Espiritualidad de la liberación se encuentra Boff (1971, p. 8), quien en su esfuerzo por adentrarse en la raíz de la vida espiritual y dar cuenta de la experiencia del Misterio en medio de la realidad histórica, afirma que "Dios solamente es real y significativo para el hombre, si surge de las profundidades de su propia experiencia" (Boff, 1971, p. 88), cuando Dios penetra en la historia de cada persona, más aún, cuando dicha presencia se evidencia en el encuentro con el otro, el hermano. De esta manera, no es posible concebir una experiencia cristiana de Dios sin la experiencia del hermano, "quien experimenta a Dios 
como Padre, experimenta al otro como prójimo y al prójimo como hermano" (Boff, 1971, p. 84).

De esta manera, la realidad y situación histórica del ser humano es para este teólogo el lugar de la experiencia de Dios cuyo proceso se plantea en tres momentos:

La experiencia inicial llega como un "saber-inmanencia-identificación", es decir, se refiere a los conceptos, al hablar y razonar sobre Dios a través del cual Él se hace inmanente. Luego, en un segundo momento, "no-saber, trascendencia-desidentificación", la experiencia se vive como constatación de la insuficiencia y vacío de las imágenes y palabras que sobre Dios podamos elaborar, para finalmente, en un tercer momento, "saber-transparencia", resignificar dichas imágenes y palabras, reconociéndolas en su insuficiencia, como nuestra posibilidad de acceso a Dios (Boff, 1971, pp. 90-91).

Para aproximarnos a la comprensión de la experiencia de Dios desde la perspectiva de Jon Sobrino (1979, pp. 25-48), es preciso antes recordar que su comprensión de la espiritualidad está enmarcada en el seguimiento de Cristo y desde allí afirma la necesidad de la oración como vía para encontrar sentido a la praxis cristiana. La oración va a suponer e implicar una experiencia de trascendencia y de sentido, una experiencia de gratuidad.

Al definir en 1979 la espiritualidad (Sobrino, 1979, p. 59) en referencia a la realidad, Sobrino (1979) plantea "la necesidad de coherencia entre el sujeto y la realidad histórica, lo cual a su vez le lleva a proponer unas exigencias fundamentales" (p. 61), entre ellas, la experiencia de Dios presentada como revelación y comunicación de Dios a través de la historia real. Así, el lugar de la experiencia de Dios es la historia en toda su complejidad y contradicción.

Según Galilea, en la espiritualidad se implican dos dimensiones claves: la contemplación y el compromiso, la dimensión mística y la dimensión política. La dimensión contemplativa-mística de la espiritualidad tiene como base la experiencia de Dios fuertemente arraigada en el mensaje de la Sagrada Escritura. Dicha dimensión supone e implica a su vez: la oración y el encuentro con el hermano, con el oprimido. La historia y sus contradicciones es lugar de encuentro y experiencia de Dios. Es preciso "saber encontrar a Jesús como Señor de la Historia en las ambigüedades de las historias actuales” (Galilea, 1977, pp. 29-32).

Para Maccise (1976, pp. 26-36), la espiritualidad no puede comprenderse sino como una experiencia de Dios: personal, evangélica y eclesial, que responde a una situación específica del hombre latinoamericano y posee una dimensión profética y contemplativa. Según este carmelita mexicano, la espiritualidad (Maccise, 2011) en América Latina comienza a replantearse gracias a la vida religiosa que provoca un movimiento hacia una espiritualidad encarnada y comprometida con los caminos de liberación; pues sin espiritualidad la liberación no puede sostenerse. Esta espiritualidad implica entre sus dimensiones fuente, la experiencia de Dios. Experiencia cuyo rasgo distintivo es el descubrimiento y vivencia 
de la acción del Espíritu en medio de la historia. Dicha experiencia puede darse por presencia y por ausencia. Esta última en América Latina se muestra como la presencia de Dios que queda oculta en la negatividad de la historia.

\section{Rasgos de la Espiritualidad de la liberación}

Después de dar cuenta de la experiencia fundamental es oportuno señalar los rasgos de la espiritualidad que dicha experiencia gestó y que Gutiérrez sistematizó en su obra central: Teología de la liberación. Perspectivas. En esta forma de ser fiel al Señor dentro del proceso de liberación serán las experiencias más significativas vividas en el pueblo pobre, las que van a configurar su particular espiritualidad. Los rasgos de la espiritualidad están íntimamente correlacionados, en cuanto configuran un modo particular de apropiar la existencia. A continuación abordaremos brevemente cada uno de ellos:

\section{Conversión}

La conversión ha sido siempre la piedra de toque de toda espiritualidad, pero dentro del proceso de liberación adquiere una particularidad, ya que dicha conversión surge del encuentro con Cristo presente en los pobres y se constituye en el centro integrador de la Espiritualidad de la liberación. Gutiérrez (1975) la concibe como "una transformación radical de nosotros mismos y un pensar, sentir y vivir como Cristo presente en el hombre despojado y alienado" (p. 268). En este sentido, la conversión implica la exigencia de un estilo de vida que frente a la realidad que se vive en América Latina, involucra una acción comprometida y solidaria con el proceso de liberación de los pobres y explotados, que incluye la transformación del medio socio económico, político, cultural, humano en que se encuentran. "Además, dicha conversión requiere de una revisión de las propias estructuras de la Iglesia y de la vida de sus miembros" (Gutiérrez, 1979, pp. 66-67).

La conversión se vive no como un hecho puntual, sino como un proceso permanente en medio de los conflictos que implican rupturas referidas a categorías mentales, a la forma de relacionarnos con los demás, de afrontar la vida, de encarnar la fe. En fin, ruptura "con todo aquello que trabe una solidaridad real y profunda con aquellos que sufren, en primer lugar, una situación de miseria e injusticia" (Gutiérrez, 1975, p. 269).

\section{Gratuidad}

“La Espiritualidad de la liberación está impregnada de una vivencia de gratuidad" (Gutiérrez, 1975, p. 269), que constituye el terreno de la libertad, del amor, de la contemplación, de la oración y la donación ilimitada, que supone el señorío y la responsabilidad ante la historia. La vivencia de la gratuidad no 
es una evasión, sino el clima en que baña una eficacia histórica buscada cada vez más ardorosamente por aquello mismo que nos revela la gratuidad: el amor preferencial de Dios por el pobre. En este sentido, vivir en el Espíritu es vivir en el amor.

Dicha gratuidad estimula el compromiso en la búsqueda de resultados basados en cálculos y el conocimiento relacional y causal de la realidad, que explicita la capacidad de amar como Dios ama. Pero simultáneamente crece la vivencia de la gratuidad, no como un refugio ante la impotencia histórica, sino como una exigencia de compromiso real y eficaz. Al respecto, Gutiérrez afirmará que el compromiso con el proceso de liberación de los pobres y explotados debe ser lúcido, realista y concreto, más aún, "no solo con generosidad, sino también con análisis de situación y con estrategia de acción" (Gutiérrez, 1975, p. 268).

\section{Alegría}

La alegría, como rasgo de la Espiritualidad de la liberación, está ligada a las raíces de la cultura latinoamericana en cuanto pueblo festivo. El talante cristiano de dicha experiencia de alegría y, por ende, su sentido liberador "nace del don ya recibido y todavía esperado, que se expresa en el presente, pese a la dureza y a las tensiones de la lucha por la construcción de una sociedad justa" (Gutiérrez, 1975, p. 271). Este talante de esperanza es vivido en el pueblo en la alegría, que no es fácil, pero es real. No es la alegría superficial de la inconsciencia o la resignación, sino aquella que nace de la esperanza de que el maltrato y el sufrimiento serán vencidos.

\section{Pobreza espiritual}

La pobreza espiritual es comprendida "como la total disponibilidad ante el Señor, la cual define la postura total de la existencia humana frente a Dios, los hombres y las cosas (desde una actitud de libertad ante ellas)" (Gutiérrez, 1975, p. 382). Más aún, podría comprenderse como una actitud vital, global y sintética, que dinamiza la totalidad y el detalle de nuestra vida.

Ahora bien, dicha pobreza se encarna en el compromiso de hacerse solidario frente a las situaciones que afectan la vida de los demás, pues, solo si hay una apertura y disponibilidad, es posible comprometerse con los otros. Este talante de compromiso que surge de la comprensión de la pobreza espiritual es tan fuerte en la Espiritualidad de la liberación, que Gutiérrez (1975) llega a afirmar que "solo rechazando la pobreza y haciéndose pobre para protestar contra ella, podrá la Iglesia predicar algo que le es propio: la "pobreza espiritual"; es decir, la apertura del hombre y de la historia al futuro prometido por Dios" (p. 385). 


\section{Comunidad}

La experiencia espiritual que emerge en América Latina es una experiencia comunitaria que se concreta en las diferentes comunidades eclesiales que se van convirtiendo en focos de evangelización y en motores de liberación y desarrollo. "Dios convoca, y se encarna en la comunidad de fe que se entrega al servicio de todos los hombres" (Gutiérrez, 1975, p. 30). Sin embargo, la comunidad se hace viable cuando se da la experiencia de soledad que hace posible la comunión y genera comunidad como encuentro profundo con Dios (se trata de la dimensión mística de toda espiritualidad).

En el seno de las comunidades eclesiales se gesta una manera de ser fiel a la acción del Espíritu, una espiritualidad que se enriquece con las experiencias de compromiso existencial en los caminos concretos de promoción liberadora. Además, se consolida la vocación teológica, en tanto se suscita y se ejerce en el seno de la comunidad.

\section{A manera de conclusión}

Volver la mirada hacia el origen de experiencias fundantes siempre será un ejercicio de interpelación y un espacio de renovación. Lo primero, porque el testimonio de personas que se esforzaron por vivir de manera honesta su fe pondrá en evidencia las tendencias al amaño y el acomodo en la forma de domesticar la fe. Lo segundo, porque si logramos conectarnos con el sentido espiritual que está a la base de la experiencia originaria, nos permitirá renovar nuestra manera de situarnos frente a la realidad y acoger la acción del Espíritu que mueve hacia una actitud honesta, fiel y esperanzada frente a los imperativos de la realidad histórica.

El acercamiento a los orígenes de la Espiritualidad de la liberación no solo permite recordar el carácter encarnado e histórico de la fe cristiana, sino que permite recuperar la importancia de la dimensión comunitaria de la fe y, por ende, de la vida en el espíritu que fácilmente cae presa en tendencias intimistas, privadas, espiritualistas o academicistas, que ahogan la acción del Espíritu.

En la mente de algunos, la Espiritualidad de la liberación simplemente ha pasado, pero que se diga que ha pasado es algo que se debe analizar más cuidadosamente, pues pasar no es el problema, pero sí puede serlo el simplismo con que se puede llegar a proclamar el hecho. En efecto, una cosa es pasar, en el sentido de desaparecer de la historia, y otra cosa es pasar dejando en la historia algo perenne, en el sentido de clásico. Esta segunda connotación es la que se corresponde con la Espiritualidad de la liberación, pues mientras haya realidades que atenten contra la vida en todas sus manifestaciones y la dignidad del ser humano, el Espíritu conducirá desde dentro de la realidad histórica, a quienes lo acojan, a asumir un modo de existencia comprometido en función de la liberación. 


\section{Referencias}

Assmann, H. (1971). Opresión-liberación. Desafío a los cristianos. Montevideo: Tierra Nueva.

Boff, L. (1975). La experiencia de Dios. Bogotá: Indoamerican.

Concilio Ecuménico Vaticano II. (1991). Constitución pastoral Gaudium et Spes, sobre la iglesia en el mundo actual. Bogotá: Paulinas.

Consejo Episcopal Latinoamericano, Celam. (1987). Conclusiones, La Iglesia en la actual transformación de América Latina a la luz del Conclio. Medellín.

Ellacuría, I. (1971). Liberación: misión y carisma de la Iglesia latinoamericana. ECA, (268), 61-80.

Ellacuría, I. (1984). Conversión de la Iglesia al reino de Dios para anunciarlo y realizarlo en la historia. Santander: Sal Terrae.

Ellacuría, I. (1990). Historicidad de la salvación cristiana. Mysterium Liberationis, (1). San Salvador: UCA.

Ellacuría, I. (1993). Liberación. Revista Latinoamericana de Teología, (30), 213-232.

Galilea, S. (1977). La Espiritualidad de la liberación como espiritualidad política. Christus, (499), 29-32.

Gutiérrez, G. (1975). Teología de la liberación. Perspectivas. Salamanca: Sígueme.

Gutiérrez, G. (1979). Pobres y liberación en Puebla. Diakonía, (10), 39-69.

Gutiérrez, G. (1983). Beber en su propio pozo. Lima: CEP.

Gutiérrez, G. (1989). El Dios de la vida. Lima: Instituto Fray Bartolomé de las Casas.

Iriarte, G. (1993). ¿Qué es una comunidad eclesial de base? México: Dabar.

Maccise, C. (1976). Espiritualidad de la vida religiosa hoy en América Latina. Christus, (488), 29-36.

Maccise, C. (2007). Aportes de la vida religiosa a la Espiritualidad de la liberación. Aportes de la vida religiosa a la teología latinoamericana y del Caribe. Hacia el futuro, 422-450. Recuperado de http://clar.org/clar/index.php?module=C ontenido\&type=file\&func $=$ get $\&$ tid $=3 \&$ fid $=$ descarga\&pid $=61$ 
Maccise, C. (2011). Entrevista, Passim. Concedida por C. Maccise, vía Skype, desde México, D.F., en octubre de 2011 a los miembros del Grupo de Investigación Academia.

Mora, J. (1999). Para leer a Ignacio Ellacuría, X aniversario de su asesinato, curso 99/00. Recuperado de http://ensayistas.org/filosofos/spain/ellacuria/critica/ mora-g4.htm

Oliveros, R. (1990). Historia de la Teología de la liberación. Recuperado de http:// servicioskoinonia.org/relat/300.htm

Pikaza, X. (2010). Diccionario de pensadores cristianos. Estella (Navarra): Verbo Divino.

Sobrino, J. (1979). Espiritualidad de Jesús y de la liberación. Christus, (529-530), 59-63.

Sobrino, J. (1977). La oración de Jesús y del cristiano. Christus, 42(500), 25-48.

Sols, J. (1999). La teología histórica de Ignacio Ellacuría. Madrid: Trotta. 